\title{
I Need Your Love: Self-Stigma And Classification Of Communication Patterns Required By Breast Cancer Patients
}

Saidatun Najmiah Mohd Jamil, Jusang Bolong, Mohd Nizam Osman, Tham Jen Sern

To Link this Article: http://dx.doi.org/10.6007/IJARBSS/v12-i1/12356

DOI:10.6007/IJARBSS/v12-i1/12356

Received: 18 November 2021, Revised: 21 December 2021, Accepted: 06 January 2022

Published Online: 27 January 2022

In-Text Citation: (Jamil et al., 2022)

To Cite this Article: Jamil, S. N. M., Bolong, J., Osman, M. N., \& Sern, T. J. (2022). I Need Your Love: Self-Stigma And Classification Of Communication Patterns Required By Breast Cancer Patients. International Journal of Academic Research in Business and Social Sciences, 12(1), 2773-2781.

Copyright: (c) 2022 The Author(s)

Published by Human Resource Management Academic Research Society (www.hrmars.com)

This article is published under the Creative Commons Attribution (CC BY 4.0) license. Anyone may reproduce, distribute, translate and create derivative works of this article (for both commercial and non0-commercial purposes), subject to full attribution to the original publication and authors. The full terms of this license may be seen at: http://creativecommons.org/licences/by/4.0/legalcode

Vol. 12, No. 1, 2022, Pg. $2773-2781$

Full Terms \& Conditions of access and use can be found at http://hrmars.com/index.php/pages/detail/publication-ethics 


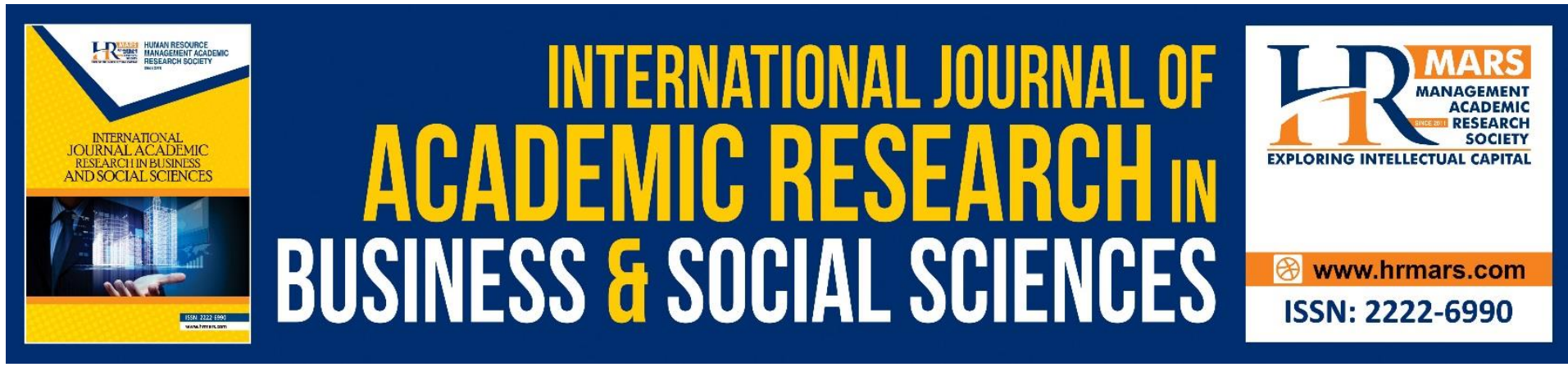

\title{
I Need Your Love: Self-Stigma And Classification Of Communication Patterns Required By Breast Cancer Patients
}

\author{
Saidatun Najmiah Mohd Jamil, Jusang Bolong, Mohd Nizam \\ Osman, Tham Jen Sern \\ Communication Department, Faculty of Modern Languages and Communication, \\ Universiti Putra Malaysia, Malaysia, Serdang
}

\begin{abstract}
Cancer patients desperately require supports from their partners or family members for survival. Various forms of supports either explicitly or implicitly are anxiously needed by them, especially in terms of communication supports to reduce the implications of negative selfstigma faced by them. This article aims to discuss the classification of appropriate communication patterns practiced by spouses and family members of these patients. Researchers suggest that there are four classifications of communication patterns that can be implemented to communicate with breast cancer patients, such as primary communication pattern, secondary communication pattern, linear communication pattern and circular communication pattern. Researchers discovered that these four communication patterns can be practiced by spouses and families of cancer patients to help them control and cope with emotions during treatment.
\end{abstract}

Keywords: Self-Stigma, Communication Patterns, Cancer Patients, Cancer Spouses And Breast Cancer

\section{Introduction}

Cancer is a chronic disease that contributes to mortality rates worldwide, yet the life expectancy of a patient to survive can be extended from an appropriate period of time in line with technological advances in medicine (Albert et al., 2017). Patients with cancer will experience problems involving self, physical, cognitive, role and social functioning. Due to these problems faced by these patients, their dependency on families and spouses becomes high.

Most of the caregivers involved face problems in managing and assisting cancer patients due to lack of knowledge, skills and support resources to handle tasks in this care (Albert et al., 2017). If these are not rectified, their situations will worsen thus indirectly contribute to the burden and stress of their caregivers. The crucial part in helping cancer patients is to understand the self-stigma they have. 


\section{Self-Stigma and Community Stigma Among Breast Cancer Patients}

Self-stigma plays a major role in cancer patients. Positive self-stigma encourages cancer patients to remain enthusiastic in going through their daily routines. Various studies have been conducted related to the management of self-stigma. A study conducted by Tsai \& Lu (2019) found that breast cancer patients can reduce the level of self-stigma by writing down their cancer-related beliefs to help them translate their emotions personally without having to think about the views of others. In addition, this study also found that the relationship of patients with the same background also benefits them. Understanding the stigma that exists in cancer patients can also be linked to the implications that occur to them.

Self-stigma is also known as internal stigma resulting from societal stigma accepted by individuals. Societal stigma refers to societal attitudes or beliefs about mental health. Selfstigma and societal stigma will lower an individual's self-esteem where both of these types of stigmas have negative impacts on most individuals who avoid getting help or supports related to mental health (Crowe et al., 2018). However, individuals who receive societal stigma will not necessarily also accept the problem of self-stigma in which it only occurs in individuals who form negative attitudes that further worsen their health as well as themselves (Kato et al., 2017). To reduce the negative implications of self and societal stigma, stigma communication should be considered to help cancer patients.

\section{Stigma Communication}

A study conducted by Shiri et al (2018) discovered that stigma communication occurs among breast patients due to the neglect and rejection by partners, lack of family supports, formal supports, treatment differences, changes in interaction with family members, and the avoidance from attending social places where family members make a big impact in the process for the patient to recover.

\section{Couple Communication with Breast Cancer Patients}

A study conducted by Xu et al (2019) discovered that there is a tendency, either from patients or partners, to reveal negative or less positive information related to breast cancer in daily life. However, this study also found that the perceptions of positive information are a mediator between the disclosure of positive or negative information and recurrent cancer anxiety.

In comparison, a study by Lillie et al (2018) using Communicative Theory of Resilience (CTR) discovered that couples with breast cancer can build relationships by building new norms, enhancing identity through religion and motherhood, focusing on positive actions when discussing negative emotions, and also using logical alternative approaches in a form of beauty as well as humor.

\section{Classification of Communication Patterns Communication}

Patterns consist of four categories, namely (1) Primary communication pattern; (2) Secondary communication pattern; (3) Linear communication pattern; and (4) Circular communication pattern (Andriani et al., 2019). These patterns of communication are a form of recommendation that can be given attention by spouses and family members of cancer patients. 
Figure 1: Types of Communication Patterns

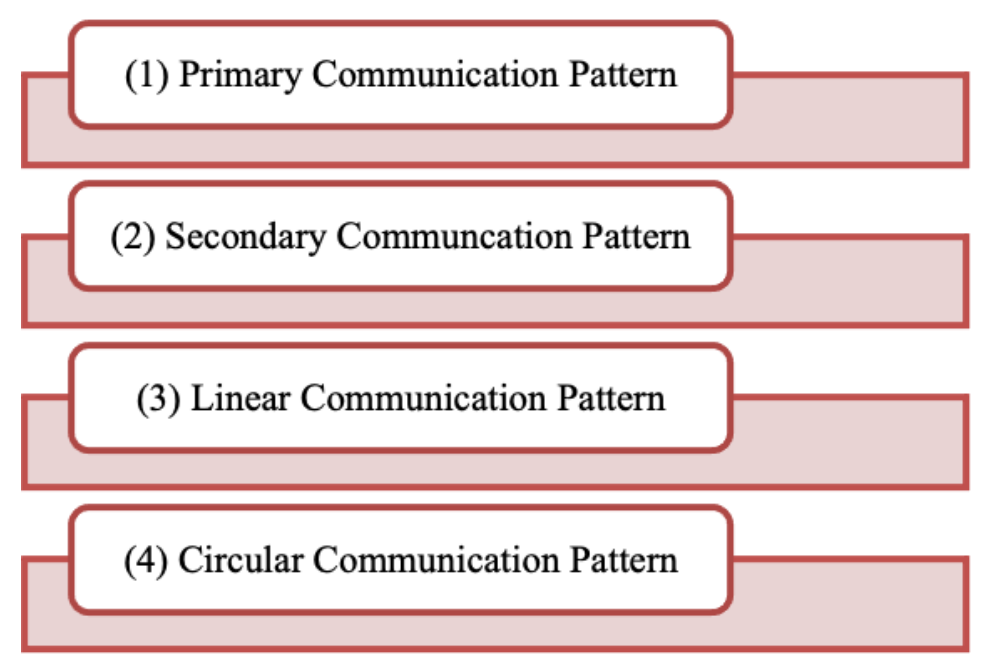

\section{1) Primary Communication}

Primary communication pattern is a process of conveying thoughts by a communicator to a communicant by using a symbol (symbol) as a medium or channel. This pattern is divided into two symbols, namely verbal symbols and nonverbal symbols. Verbal symbol in a language is the most important and most often used verbal symbol because a language is able to express the thoughts of communicators. Nonverbal symbols are symbols used to communicate other than languages. It is a gesture with limbs such as eyes, head, lips, and hands. In addition, images are also symbols of nonverbal communication, therefore, by combining the two, the communication process in this pattern will be more effective (Purwasito, 2020; Saputra, 2013).

In this regard, a study conducted by Shiri et al (2020) found that stigma among cancer patients at an individual or family level requires increased awareness, problem-solving education, supports including counselling. On the other hand, at a community level requires cultural change and also education to benefit the physical and psychological well-being of patients as well as change society's attitude towards cancer. This includes early screening in order to reduce more serious implications and death rates from cancer.

For example, stigma resulting from an experience or acceptance of societal stigma is likely to lower the level of chronic patient self-care where patient self-care consists of patient's knowledge, skills, confidence, and behaviors to manage their disease (Kato, et al., 2020). This situation occurs because both types of stigmas refer to factors of attitude (prejudice), belief (stereotype), and behavior (discrimination) (Hasan \& Musleh, 2018).

For example, stigma about body shape is not determined based on individual feelings (prejudice) towards weight but is measured based on societal beliefs (stereotypes) towards weight and negative individual evaluations (discrimination) towards the weight of others (Sevincer et al., 2017).

\section{2) Secondary Communication}

Secondary communication pattern is the delivery of a message by a communicator to a communicant by using tools or means as a second medium after using symbols on the 
medium first. Communicators use this second medium because it is the target of communication that is far away, or in large numbers.

In this secondary communication process, the longer it takes the more effective and efficient it will be, as it is supported by increasingly sophisticated communication technologies. This pattern of communication is based on a simple model created by Aristotle, thus influenced Harold D. Lasswell, an American political scholar who later created a communication model known as the Lasswell formula in 1984 (Purwasito, 2020; Saputra, 2013).

A study conducted by Tsai \& Lu (2019) found that breast cancer patients can reduce the level of self-stigma by writing down their cancer-related beliefs to help them translate their emotions personally without having to think about the views of others. In addition, this study also found that the relationship of patients with the same background also benefits them.

However, a study conducted by Lawlor \& Kirakowski (2014) found that online support to breast cancer patients has a negative impact on self-stigma because it causes them to rely too much on online support, which in turn causes their weaknesses to be more exposed.

In comparison, a study conducted by Alvarez-Mon, et al (2019) found that the use of Twitter, one of the most popular social media globally, can reduce the problem of stigma among breast cancer patients because the analyzed 'tweets' (tweets) provide accurate information related to medicine and Twitter can be used as a communication medium for anti-stigma campaigns.

\section{3) Linear Communication}

Linear communication pattern here refers to the journey from one point to another in a straight line, which means the delivery of a message by a communicator to a communicant as a terminal point. This communication process usually occurs in communication (face-to-face), but sometimes through media communication. In this communication process, messages conveyed will be effective if there is planning before implementing the communication. Shannon and Weaver (1949) applied the process of human communication (human communication) which is rooted in mathematical theory in mechanical communication (engineering communication). The mathematical model describes communication as a linear process (Purwasito, 2020; Saputra, 2013).

A study conducted by Warmoth et al (2017) found that counselling services provided to breast cancer patients can reduce stigma. Additionally, a patient communication with family members as well as counselling services can help disseminate information related to breast cancer diagnosis and related health insurance in order to help patients recover.

According to a study conducted by Kayser \& Acquati (2019), there are communication problems that occur between breast cancer patients and partners due to lack of communication skills or there are barriers in relationships such as abuse either from physical or emotional aspects and prolonged conflict and no solution preventing patients and spouses from interacting with each other. 
For this reason, a study conducted by Badr (2017) found that communication between spouses and cancer patients consists of communication components involving cancer-related sensitivities, engaging in social support, negotiating about role changes in life, and coordination to cope with illness.

\section{4) Circular Communication Pattern}

One of the patterns used to describe the communication process is the circular pattern made by Osgood and Schramm. Both of these figures focused their attention on the role of source and receivers as key actors of communication. This pattern describes communication as a dynamic process, in which messages are transmitted through a process of encoding and decoding. Encoding is the transference performed by a source of a message, and decoding is the transference performed by the recipient of the message coming from the source. The relationship between encoding and decoding is the relationship between a source and a receiver stimulating and mutually influencing each other (Purwasito, 2020; Saputra, 2013).

As a dynamic process, an interpreter in this circular pattern has two functions, namely as a sender and receiver of a message. In the early stages, the source serves as an encoder and the receiver as a decoder. But at the next stage the receiver functions as the sender (encoder) and the source as the receiver (decoder), in other words the first source will be the second receiver and the first receiver functions as the second source, and so on (Purwasito, 2020; Saputra, 2013).

Self-stigma occurs when individuals are 'aware' (prejudice) of beliefs (stereotypes) built by the surrounding society and begin to 'agree' (discriminate) with a belief (Bonfils, et al., 2018). This situation occurs because the stigma formed by individuals will cause them to feel fear of attitudes from others such as ridicule, bias or discrimination in turn influencing negative behaviors to overcome the resulting fears of others (Lillis et al., 2020).

To explain this, the concept of stigma consists of six components of a process that occur simultaneously. These components include labelling and identifying differences; giving negative credence to people who are labelled differently; distinguishing between labelled and unlabelled individuals ('we' and 'they'); emotional reactions to both labelled and labelled parties; labelled parties experience discrimination and loss of status; and influence social, political, and economic forces to make all components of the process take place (Chang et al., 2018).

In short, the stigma of society will cause sufferings among individuals and their number is increasing as well as forming a minority group in society (Adam et al., 2019). To explain this situation, the Stigmatization Model describes the symptoms of stigma in the context of social, cultural, economic, and political power. Additionally, individuals or groups labelled will continue to lose rights throughout life such as access to education, income, and use of health services where "discrimination and loss of status "will reduce stigma by" everything is normal" by hiding or being careful to reveal the stigma problem experienced (Seo \& Song, 2019).

In addition, Huang et al (2020) reported that stigma due to cancer had a significant relationship with self-perceptions of age, anger, self-blame, stressful living situations, carrying 
problems alone, and insomnia but had no relationship with communication by treatment providers and sleep quality.

In general, the group of female patients with self-stigma is higher than male patients whereas female patients who are still single have a higher self-stigma compared to female patients who are married (Komatsu, et al., 2020). In comparison, parents of individuals with self-stigma also experience the problem of self-stigma if their children are constantly discriminated against by society because self-stigma stems from the individual's internal communication towards self and subsequently form negative thoughts about self whose effects are more harmful than stigma resulting from prejudiced public perceptions (Chan \& Leung, 2021). For this reason, health communication campaigns today have shifted from disseminating information and education in general to social marketing techniques by focusing on efforts to change individuals behaviors (Lefebvre, et al., 2020).

\section{Conclusion}

Communication factors play an important role as they can influence the psychology of patients, spouses, and family members. In conclusion, it is important for couples and family members of breast cancer patients to identify the appropriate types of communication patterns to avoid problems that can lead to stigma that is negative individual beliefs. Among the beliefs are insecurity, inadequacy, threatened, depressed, troubled, unhappy, weak, or disturbed because social identity is not valued in a social context, thus affecting their level of mental health.

Thus, couples with breast cancer can build relationships by building new norms, enhancing identity through religion and motherhood, focusing on positive actions when discussing negative emotions, and even using logical alternative approaches in a form of beauty as well as humor if the type of communication pattern is suitable to be used by the patient's spouse and family members.

\section{Acknowledgement}

I would like to express my sincere gratitude to my supervisor, Associate Professor Dr. Jusang Bolong, for your patience, guidance, and support. I have benefited greatly from your wealth of knowledge and meticulous editing. I am extremely grateful that you took me on as a student and continued to have faith in me over the years. Thank you to my committee members, Associate Professor Dr. Mohd Nizam Osman and Dr. Tham Jen Sern. Your encouraging words and thoughtful, detailed feedback have been very important to me.

Most importantly, I am grateful for my husband, precious little princess and family's unconditional, unequivocal, and loving support. Last but not the least I would also like to thank all of my friends for encouraging and supporting me whenever I needed them.

Special tribute to my late sister, Allahyarhamah Nur Syamsyiah binti Che Soriah who passed away after a long battle with Triple Negative Breast Cancer (TNBC). May Allah swt shower her with HIS love and grant her the highest place in Jannah. (Alfatihah)

\section{Corresponding Author}

Saidatun Najmiah Mohd Jamil

Malaysia, PhD in Human Communication, Universiti Putra Malaysia 
Email: saidatunnajmiah@yahoo.com

\section{References}

Adam, A., Badwi, A., \& Palutturi, S. (2019). Analysis of factors associated with self-stigma (PLHIV) on the HIV and AIDS incidencein Jongaya positive care supporting group of Makassar City. Indian Journal of Public Health Research \& Development, 10(11), 25072512.

Albert, W. K. G., Ahmed Hatta, Z., \& Fahrudin, A. (2017). Pengalaman keluarga dalam penjagaan pesakit kanser. Asian Social Work Journal, 2 (1), 53 - 63). https://media.neliti.com/media/publications/322815-the-experience-of-familycaregivers-livi-fe5e6842.pdf

Alvarez-Mon, M. A., Llavero-Valero, M., Sánchez-Bayona, R., Pereira-Sanchez, V., Vallejo-

Valdivielso, M., Monserrat, J., \& Alvarez-Mon, M. (2019). Areas of interest and stigmatic attitudes of the general public in five relevant medical conditions: Thematic and quantitative analysis using Twitter. Journal of Medical Internet Research, 21(5), 1-11.

Andriani, L., Zubair, A., \& Gusfa, H. (2019). Communication pattern of participation of women through Facebook walls in the presidential election of the republic of Indonesia in 2019. Advances in Social Science, Education and Humanities Research, 343, 495-500.

Badr, H. (2017). New frontiers in couple-based interventions in cancer care: Refining the prescription for spousal communication. Acta Oncologica, 56(2), 139-145.

Bonfils, K. A., Lysaker, P. H., Yanos, P. T., Siegel, A., Leonhardt, B. L., James, A. V., \& Davis, L. W. (2018). Self-stigma in PTSD: Prevalence and correlates. Psychiatry Research, 265, 712.

Chan, K. K., \& Leung, D. C. (2021). Linking child autism to parental depression and anxiety: The mediating roles of enacted and felt stigma. Journal of Autism and Developmental Disorders, 51(2), 527-537.

Chang, C.-C., Lin, C.-Y., Gronholm, P. C., \& Wu, T.-H. (2018). Cross-validation of two commonly used self-stigma measures, Taiwan versions of the internalized stigma mental illness scale and self-stigma scale-short, for people with mental illness. Assessment, 25(6), 777-792. doi:10.1177/1073191116658547

Crowe, A., Mullen, P. R., \& Littlewood, K. (2018). Self-stigma, mental health literacy, and health outcomes in integrated care. Journal of Counseling \& Development, 96(3), 267277.

Hasan, A. A., \& Musleh, M. (2018). Self-stigma by people diagnosed with schizophrenia, depression and anxiety: Cross-sectional survey design. Perspectives in Psychiatric Care, 54(2), 142-148.

Huang, Z., Yu, T., Wu, S., \& Hu, A. (2020). Correlates of stigma for patients with cancer: A systematic review and meta-analysis. Supportive Care in Cancer, 1-9.

Kato, A., Fujimaki, Y., Fujimori, S., Isogawa, A., Onishi, Y., Suzuki, R., \& Hashimoto, H. (2017).

Psychological and behavioural patterns of stigma among patients with type 2 diabetes: A cross-sectional study. BMJ Open, 7(3), e013425.

Kato, A., Fujimaki, Y., Fujimori, S., Isogawa, A., Onishi, Y., Suzuki, R., \& Hashimoto, H. (2020). How self-stigma affects patient activation in persons with type 2 diabetes: A crosssectional study. BMJ Open, 10(5), e034757.

Kayser, K., \& Acquati, C. (2019). The influence of relational mutuality on dyadic coping among couples facing breast cancer. Journal of Psychosocial Oncology, 37(2), 194-212.

Komatsu, H., Ono, T., Maita, Y., Ishida, Y., Kikuchi, T., Maki, T., \& Kakuto, Y. (2020). Association 
between autistic symptoms and self-stigma in patients with schizophrenia spectrum disorders. Neuropsychiatric Disease and Treatment, 16, 2553-2561.

Lawlor, A., \& Kirakowski, J. (2014). Online support groups for mental health: A space for challenging self-stigma or a means of social avoidance?. Computers in Human Behavior, 32, 152-161. doi:10.1016/j.chb.2013.11.015

Lefebvre, R. C., Chandler, R. K., Helme, D. W., Kerner, R., Mann, S., Stein, M. D., \& Rodgers, E. (2020). Health communication campaigns to drive demand for evidence-based practices and reduce stigma in the HEALing Communities Study. Drug and Alcohol Dependence, 217, 108338. doi:10.1016/j.drugalcdep.2020.108338

Lillie, H. M., Venetis, M. K., \& Chernichky-Karcher, S. M. (2018). "He would never let me just give up": Communicatively Constructing Dyadic Resilience in the experience of breast cancer. Health Communication, 33(12), 1516-1524.

Lillis, J., Thomas, J. G., Levin, M. E., \& Wing, R. R. (2020). Self-stigma and weight loss: The impact of fear of being stigmatized. Journal of Health Psychology, 25(7), 922-930.

Purwasito, A. (2002). Komunikasi Multikultural. Surakarta: Muhammadiyah University Press.

Saputra, A. (2013). Pola komunikasi: Produksi program acara talkshow Sakinah. Undergraduate (S1) thesis, IAIN Kediri. Fakultas Ekonomi dan Bisnis Jurusan Ekonomi Syariah. http://etheses.iainkediri.ac.id/573/

Seo, K., \& Song, Y. (2019). Self-stigma among Korean patients with diabetes: A concept analysis. Journal of Clinical Nursing, 1794-1807. doi:10.1111/jocn.14789

Sevincer, G. M., Kaya, A., Bozkurt, S., Akin, E., \& Kose, S. (2017). Reliability, validity, and factorial structure of the Turkish version of the weight self-stigma questionnaire (Turkish WSSQ). Psychiatry and Clinical Psychopharmacology, 27(4), 386-392.

Shiri, F. H., Mohtashami, J., Manoochehri, H., \& Rohani, C. (2018). Explaining the meaning of cancer stigma from the point of view of Iranian stakeholders: A qualitative study. International Journal of Cancer Management, 11(7), 1-8.

Shiri, F. H., Mohtashami, J., Manoochehri, H., Nasiri, M., \& Rohani, C. (2020). Care plan for reducing stigma in cancer. Open Journal of Nursing, 10, 1142-1154. doi:10.4236/ojn.2020.1011081

Tsai, W., \& Lu, Q. (2019). Ambivalence over emotional expression and intrusive thoughts as moderators of the link between self-stigma and depressive symptoms among Chinese American breast cancer survivors. Journal of Behavioral Medicine, 42(3), 452-460.

Warmoth, K., Cheung, B., You, J., Yeung, N. C., \& Lu, Q. (2017). Exploring the social needs and challenges of Chinese American immigrant breast cancer survivors: A qualitative study using an expressive writing approach. International Journal of Behavioral Medicine, 24(6), 827-835.

$\mathrm{Xu}$, W., Wang, J., \& Schoebi, D. (2019). The role of daily couple communication in the relationship between illness representation and fear of cancer recurrence in breast cancer survivors and their spouses. Psycho-oncology, 28(6), 1301-1307. 